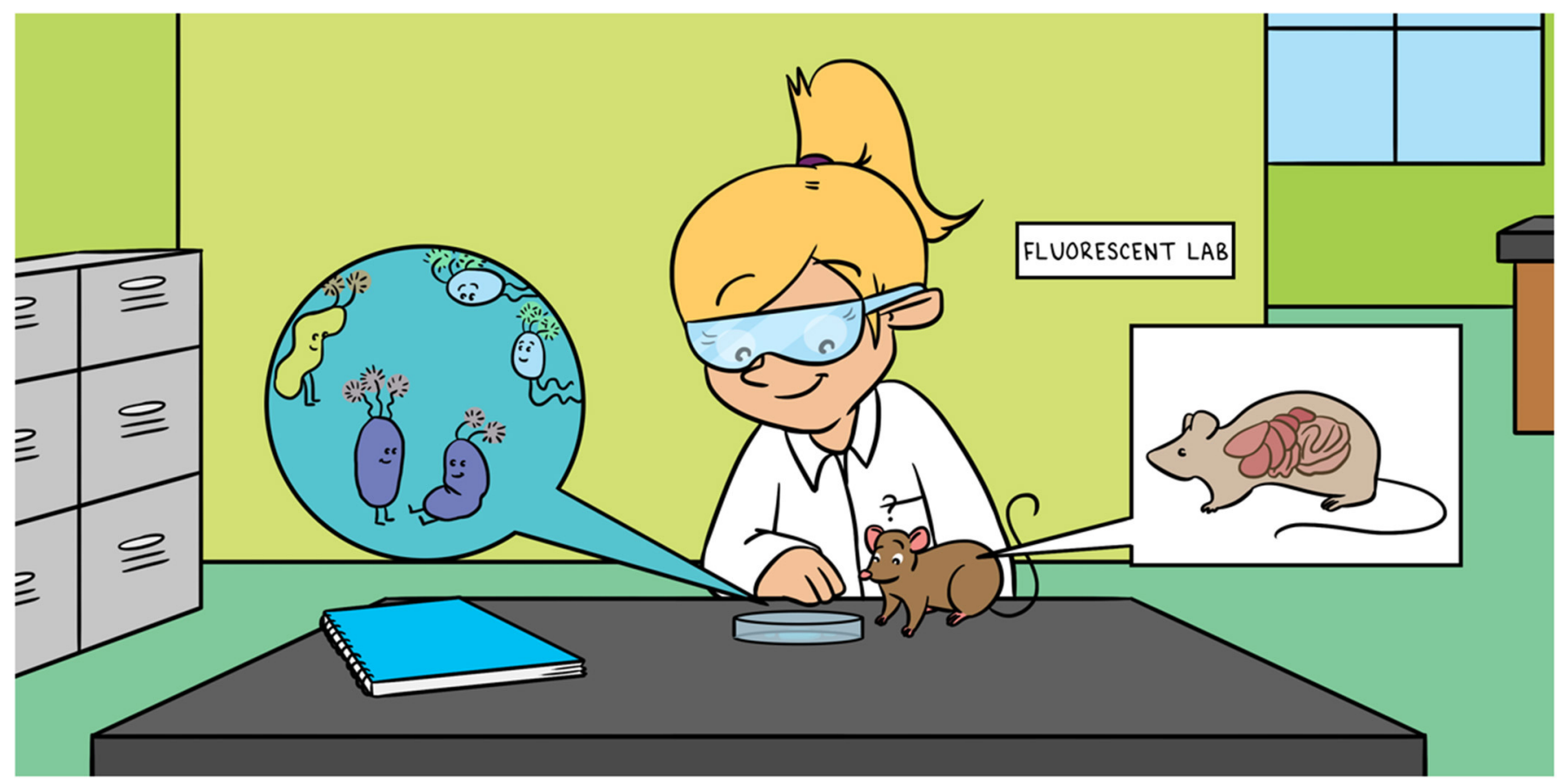

\title{
LET THERE BE LIGHT-A RARE GLIMPSE INTO THE LIVES OF OUR GUT BACTERIA
}

\section{Anna Golberg and Naama Geva-Zatorsky*}

Rappaport Faculty of Medicine, Technion - Israel Institute of Technology, Haifa, Israel

YOUNG REVIEWERS:

8TH GRADE, WIZO

NAHALAL

SCHOOL

AGES: $13-14$

\section{MICROBIOTA}

A general name for all the bacteria living in the body.
Our gut bacteria influence multiple physiological process including the immune response of our body. In this article, we describe a method for labeling anaerobic gut bacteria with a fluorescent marker that reflects light if it is illuminated, just like light reflectors on our bikes. This marker can be identified by a special microscope. Using this marker, we can act as detectives and track the activity of our gut bacteria in their natural environment. This method allowed us to see the interaction of bacteria with various immune system cells and where the bacteria chose to settle along the digestive system.

\section{OUR GUT BACTERIA}

The human digestive system hosts about 1.5 kilograms of bacteria, called the microbiota, living peacefully within us. Most of these bacteria are not harmful and even help us deal with harmful bacterial invaders or viruses. During evolution, these bacteria developed an important relationship with the immune system, in which they significantly influence its development and functioning. However, 
PEPTIDOGLYCANS

Large molecules composed of sugars and proteins that provide structural strength to the bacterial cell wall.

\section{FLUORESCENT}

A light that is reflected when illuminated.

\section{ANAEROBIC}

Without oxygen. Anaerobic bacteria require an oxygen free environment in order to live. when this relationship gets out of balance, many diseases can develop. Therefore, it is very important to study the composition of the microbiota and the interactions of these bacteria with the body's cells.

Bacteria are single-celled organisms. Their cells are covered with a stiff wall that protects them and is necessary for their survival. The bacterial cell wall is built from layers of peptidoglycans, which are large molecules comprised of sugars and proteins. Bacteria can be divided into two major groups based on the cell wall composition. One group is called Gram-positive bacteria, and the second group is called Gram-negative bacteria. They are named after the Danish doctor Hans Christian Gram, who developed a special staining technique that allowed him to tell the two groups apart. Gram-positive bacteria have a thick envelope built from many layers of peptidoglycans. Gram-negative bacteria have a thinner envelope built from a few layers of peptidoglycans, but which also contains a special layer composed of sugars, proteins, and fats. These big molecules are located on the outside of the cell wall and are used to communicate with the environment. The cells of the human immune system know how to recognize those specific molecules, and that is how some bacteria can communicate with and activate the body's immune response.

One type of Gram-negative bacteria, called Bacteroides fragilis, is a common type of bacteria in the human gut. It covers itself with a layer of unique sugars. These sugars can "talk" with the human immune system and reduce its activity, thereby protecting us against various inflammatory diseases that are caused by an overactive immune system. Because $B$. fragilis is so common and important for a balanced gut microbiota, we decided to focus on it in our experiments.

\section{TRACKING BACTERIA WITH A FLUORESCENT PROTEIN}

The most common method for tracking biological processes is to use a protein called green fluorescent protein (GFP). This protein was first discovered in glowing jellyfish in the deep sea, and it is now used by researchers all over the world. In the lab, we can insert this protein into bacteria to make them shine, which allows us to see and track them (Figure 1).

GFP has one major limitation when it comes to studying the gut microbiota-GFP needs oxygen to glow, and in the depths of the gut, there are many areas that are almost completely devoid of oxygen. These areas are called anaerobic-areas with no oxygen at all. Therefore, most bacteria living in the gut are anaerobic. These bacteria require an oxygen-free environment to exist, and some can even die if they are exposed to oxygen. So, we searched for another method that would allow us to add a fluorescent marker to the anaerobic bacteria like $B$. fragilis, in the absence of oxygen. 
Figure 1

Various types of bacteria normally live in the gut, and together they are called the gut microbiota. By labeling the bacteria with different fluorescent colors, we can use a microscope to peek inside and get some clues about the lives of these bacteria, where they prefer to settle along the digestive tract, and how they communicate with the cells of the body.

\section{AZIDE GROUP}

A chemical group composed of three nitrogen atoms ( $N$ ), which is very active chemically, meaning it reacts quickly and efficiently with the right partner.

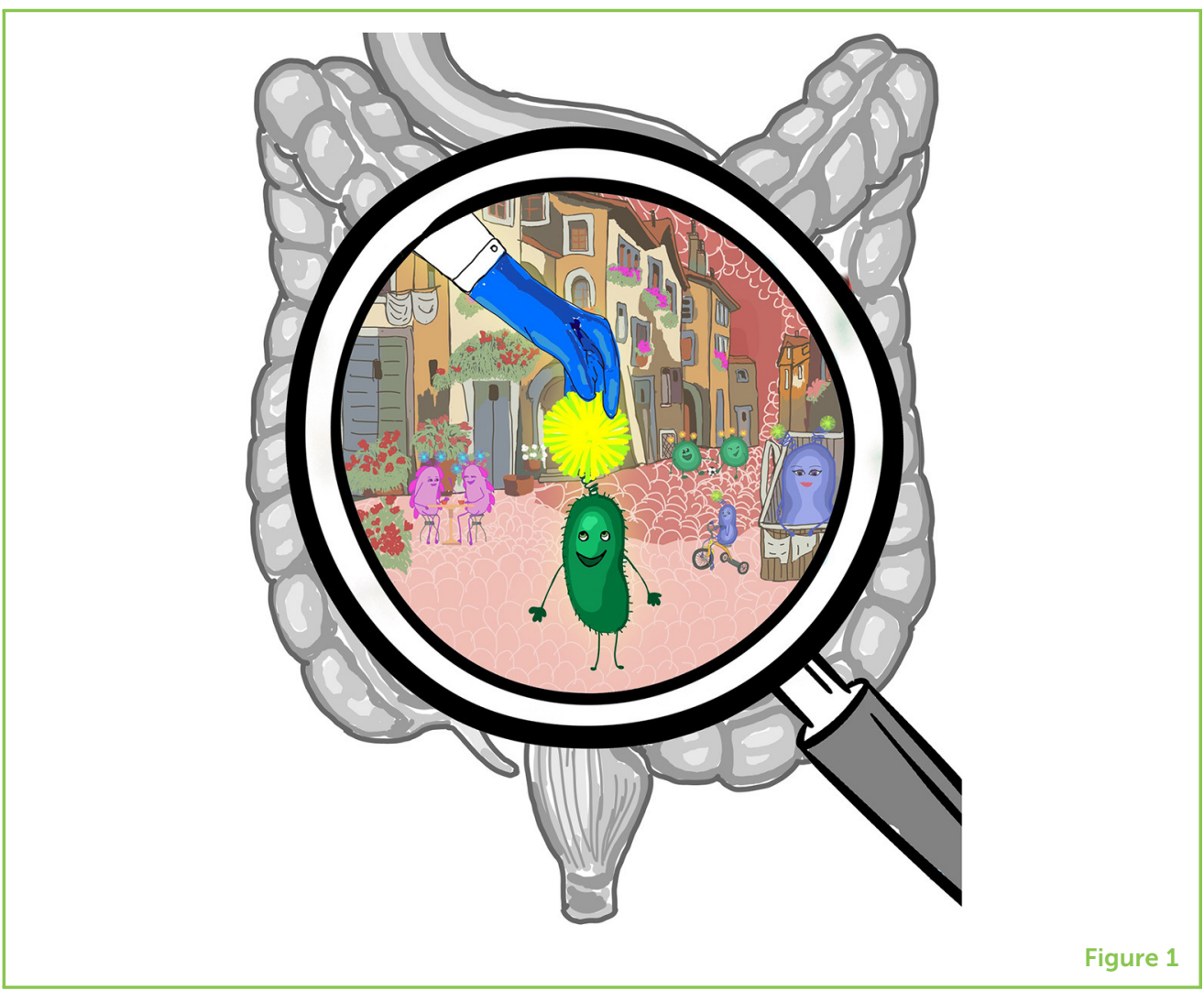

When thinking about the bacterial cell, it can be imagined as a huge chemical plant. Many different processes occur in it simultaneously, numerous chemical reactions are carried out, substances are transferred from one place to another, all with a very precise regulation and a wonderful order. When we want to learn about biological processes, we try not to interfere with what is happening in the cell. To do so, in this study, we fluorescently labeled the bacteria with external molecules that are usually not present in the cell and as such do not interfere with the natural processes within the bacteria.

\section{A NEW METHOD FOR PRODUCING FLUORESCENT BACTERIA}

Here are the details of the process we developed for making bacteria fluorescent in an oxygen-free environment (Figure 2) [1]. In the first step, a sugar molecule linked to an azide group is synthesized [2]. The azide is very active, meaning it reacts quickly with other chemical compounds. In the second step, bacteria are fed a nutritious food containing these azide-coupled sugar molecules. The bacteria eat the sugar and use it for building their cell walls. This way, the sugar molecules containing the azide groups are inserted as building blocks into the huge sugar molecules present on the outside of the bacterial cell wall. In the third step, a special fluorescent molecule, which does not require oxygen to glow, is added to the bacteria. This molecule sticks very precisely to the azide group on the bacterial surface. Using 
Figure 2

Production of

Fluorescent Bacteria.

(A) An azide group is composed of three nitrogen atoms, creating a very reactive chemical structure. (B)

Sugar with an azide group linked to it is synthesized. (C)

Bacteria consume the sugar in their food and use it to build their cell walls. (D) Chemical molecules with a fluorescent marker, which can bind to the azide group, are added to the bacteria. (E) The fluorescent molecules attach to the azide groups and turn the bacteria fluorescent. (F) A microscope photo of fluorescently labeled $B$. fragilis (A-E were produced using BioRender.com)

\section{MACROPHAGE}

A cell of the immune system capable of identifying, swallowing, and removing foreign intruders such as bacteria. Macrophages are also capable of healing wounds in the body.

\section{PHAGOCYTOSIS}

From Greek phagos = food, cytosis = cell - a process in which cells can "swallow" large particles like bacteria and break them down to small pieces.
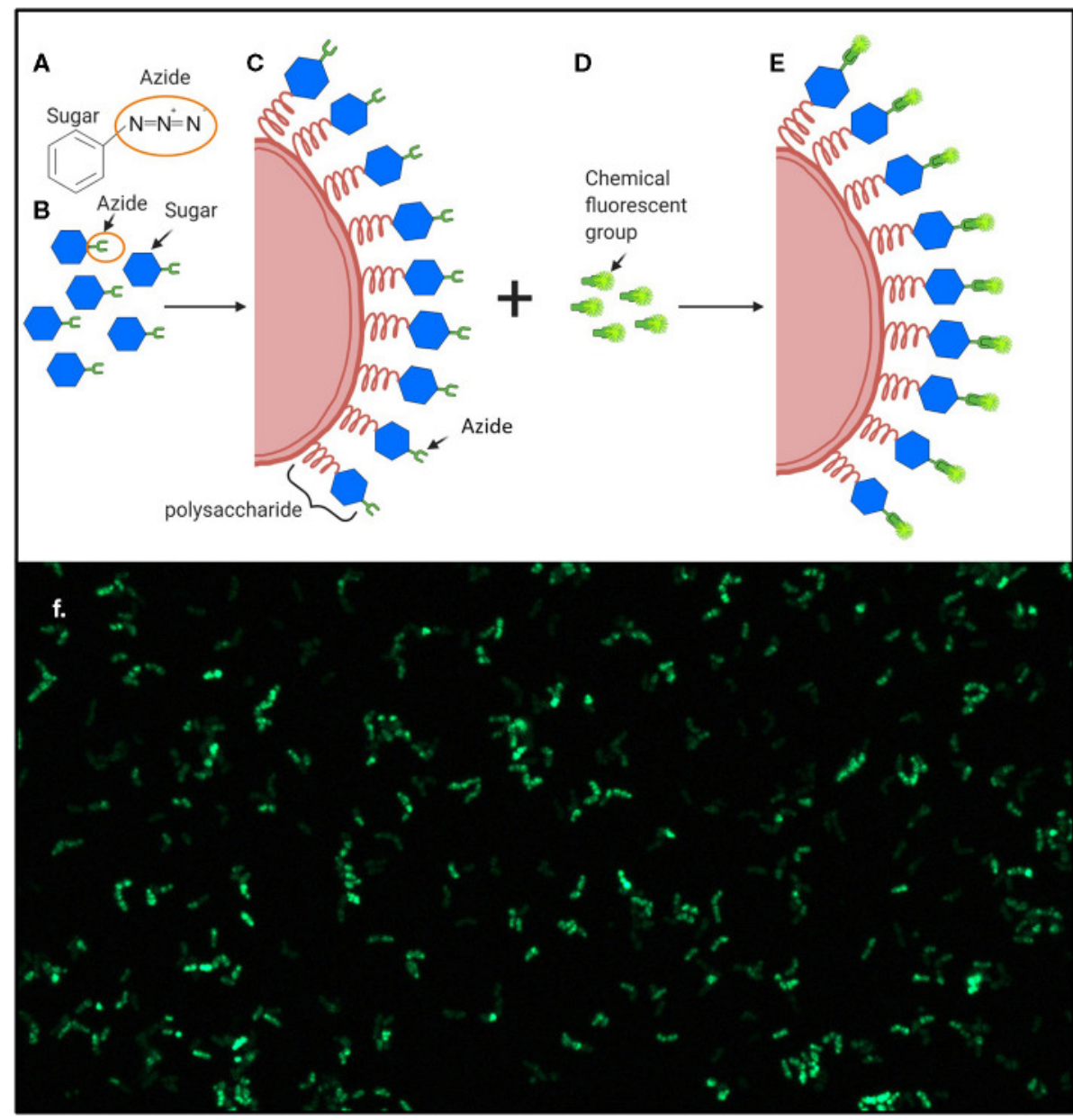

Figure 2

this method, we created bacteria that have a fluorescent label attached to their outer surface, and therefore when we illuminate them with a certain light, we can see them under the microscope and track their activity.

\section{INTERACTIONS BETWEEN BACTERIA AND IMMUNE SYSTEM CELLS}

The first thing we wanted to observe was the interaction of bacteria with different cells of the immune system, in a test tube. We used macrophages, which are cells that can be imagined as soldiers of the border guard (Figures 3A,B). Macrophages patrol the body, looking for foreign and hostile elements. Once such an element is identified, the macrophages know how to swallow and break down the foreign element, in a process called phagocytosis. We mixed macrophages with fluorescently marked $B$. fragilis and, under the microscope, we were able to see the macrophages swallowing the bacteria. 
Figure 3

Bacteria interact with cells of the immune system. Using fluorescent markers, we could identify which immune cells "talked" with the labeled bacterium. (A) "Patrolling" macrophages search for foreign intruders.

(B) When they encounter intruders, macrophages swallow them by phagocytosis and destroy them. (C) Dendritic cells also hang around in the body, alert for invaders. (D) When a dendritic cell phagocytoses an invader, it presents the foreign parts on its surface, as a "red flag" to alert other cells of the immune system to the presence of danger.

\section{DENDRITIC CELL}

A cell of the immune system that can swallow foreign intruders and present them to other cells of the immune system, so that the immune system can prepare to attack the intruder.

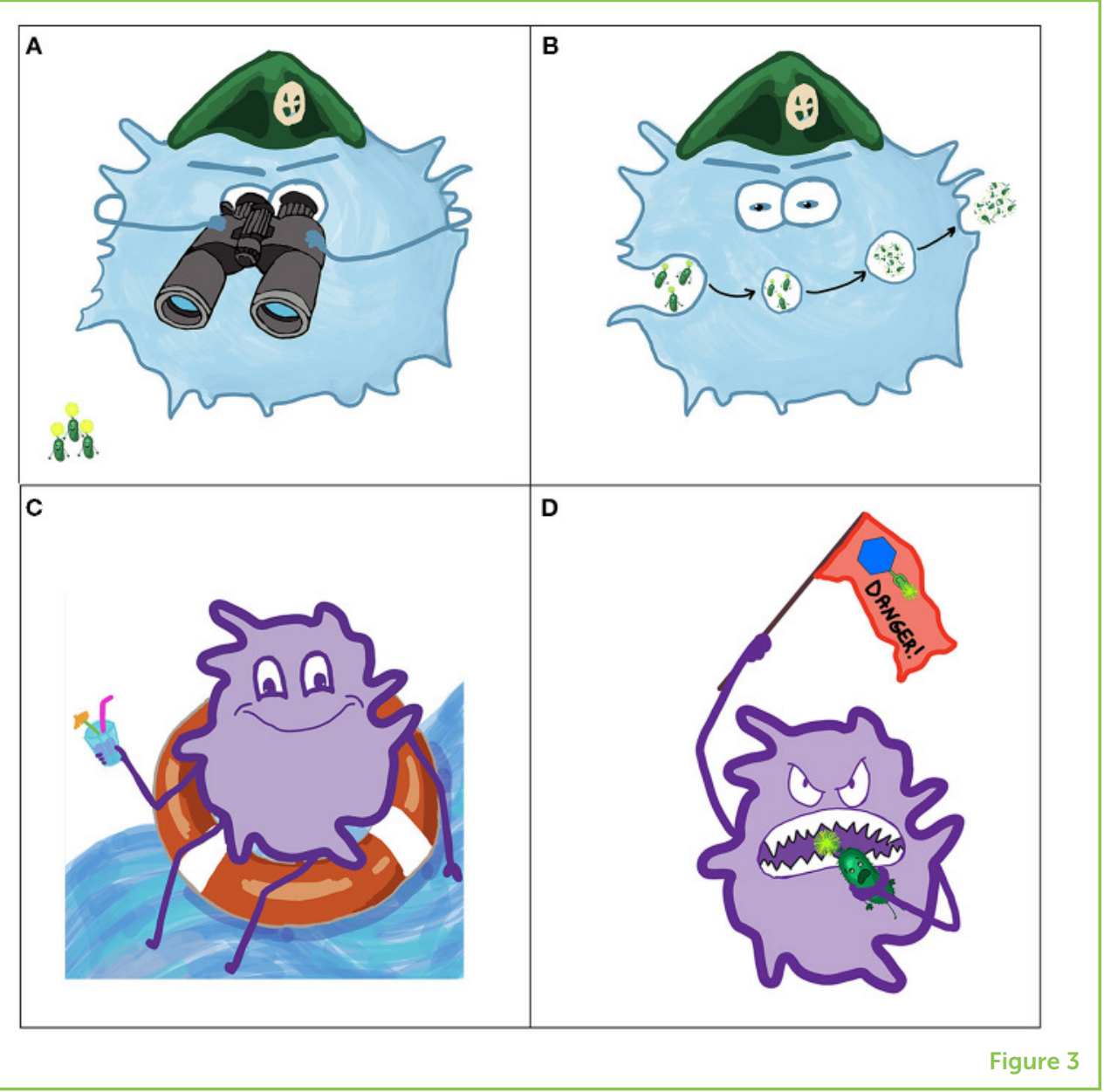

We also investigated another type of immune cells-dendritic cells (Figures 3C,D). Dendritic cells, like macrophages, can swallow foreign elements they encounter. Additionally, after breaking down the intruder, dendritic cells present parts of the intruder on their cell membranes, as a "red flag" signaling to other components of the immune system about the presence of danger. When we added fluorescently labeled $B$. fragilis to dendritic cells, we could see, using the microscope, that dendritic cells presented the fluorescent sugars, like a warning flag signaling the body about the encounter with the bacteria.

We also wanted to observe the communication between the fluorescently labeled bacteria and the immune system cells inside the body. Using our microscope, we managed to see how the labeled bacteria that caused inflammation in the belly area of a mouse, traveled to special compartments that help stop the spreading of the infection. During this journey we found the fluorescent bacteria attached to various immune system cells. 


\section{EVERY BACTERIUM HAS ITS OWN NICHE}

We were also interested in another topic: where do different kinds of bacteria choose to settle in the digestive system? Did you know that the human gut is 7.5 meters (24.6 feet) long? It looks like a pipe folded many times inside the stomach area, and it is split into three major parts - the small intestine, the large intestine, and the rectum (the final part of the large intestine). Some bacteria in the microbiota have lived inside our guts since we got them from our mothers during pregnancy. Others get there through the food we eat. Each bacterium's journey starts in the stomach, and then it travels through the pipe of the gut until it finds the most suitable environment in which to stay and build a colony.

Fluorescent $B$. fragilis were administered to a lab mouse through its mouth, and we observed the mouse with an instrument that can record the bacterium's fluorescent light. After $2 \mathrm{~h}$, we saw that most bacteria moved from the stomach to the small intestine, and after $12 \mathrm{~h}$ most bacteria were already in the large intestine. The mice we used for this first experiment had a large variety of normal bacteria in their digestive system, and those bacteria might compete with $B$. fragilis for spots to build a colony. Therefore, we also looked at mice that do not have even a single bacterium in their bodies, called germ-free (GF) mice, to study $B$. fragilis's settling preferences in the absence of competition. We added fluorescently marked $B$. fragilis to GF mice and tracked them for a couple of days. We saw that, even though there were no other bacteria in the GF mice, $B$. fragilis still chose to settle in the large intestine. From this experiment we concluded that the large intestine probably has the optimal living conditions for $B$. fragilis.

In the last part of our experiment, we labeled three types of bacteria with three different fluorescent colors, using the same method we described earlier. This way, we could tell the difference between the three types of bacteria as we tracked them. We administered all three types to a mouse, and after a while we checked where each type chose to settle. We saw that each type settled in a unique environment! Inside the gut, there are hundreds, if not thousands, of bacteria. Our work, and the work of others, shows that different types of bacteria settle in different areas of the gut, and this is one of the ways they all manage to get along together.

\section{SUMMARY}

To summarize, in our research project, we developed a method to mark anaerobic bacteria with fluorescent markers of different colors, in the absence of oxygen. With this method, we could see how Gram-negative gut bacteria communicate with certain immune cells, both in laboratory conditions as well as in the bodies of mice. We saw that different bacteria chose specific environments in which to settle 
inside the gut, both when they were competing with other bacteria and when they were not.

This work is important because anaerobic bacteria represent the vast majority of our gut microbiota. Labeling and tracking them will help us understand their role in the physiology of our body.

\section{ORIGINAL SOURCE ARTICLE}

Geva-Zatorsky, N., Alvarez, D., Hudak, J., Reading, N. C., ErturkHasdemir, D., Dasgupta, S., et al. 2015. In vivo imaging and tracking of host-microbiota interactions via metabolic labeling of gut anaerobic bacteria. Nat. Med. 21:1091-100. doi: 10.1038/nm.3929

\section{ACKNOWLEDGMENTS}

We would like to thank Haitham Hajjo for helping with the proofreading and writing. We also thank all co-authors of the original article and especially Prof. Dennis Kasper, Prof. Uli von Andrian, and Dr. David Alvarez for a fruitful and fun collaboration.

\section{REFERENCES}

1. Geva-Zatorsky, N., Alvarez, D., Hudak, J., Reading, N. C., Erturk-Hasdemir, D., Dasgupta, S., et al. 2015. In vivo imaging and tracking of host-microbiota interactions via metabolic labeling of gut anaerobic bacteria. Nat. Med. 21:1091-100. doi: 10.1038/nm.3929

2. Laughlin, S. T., and Bertozzi, C. R. 2007. Metabolic labeling of glycans with azido sugars and subsequent glycan-profiling and visualization via Staudinger ligation. Nat. Protoc. 2:2930-44. doi: 10.1038/nprot.2007.422

SUBMITTED: 17 January 2021; ACCEPTED: 08 June 2021; PUBLISHED ONLINE: 15 July 2021.

EDITED BY: Idan Segev, Hebrew University of Jerusalem, Israel

CITATION: Golberg A and Geva-Zatorsky N (2021) Let There be Light-A Rare Glimpse Into the Lives of Our gut Bacteria. Front. Young Minds 9:654760. doi: 10. 3389/frym.2021.654760

CONFLICT OF INTEREST: The authors declare that the research was conducted in the absence of any commercial or financial relationships that could be construed as a potential conflict of interest.

COPYRIGHT @ 2021 Golberg and Geva-Zatorsky. This is an open-access article distributed under the terms of the Creative Commons Attribution License (CC BY). The use, distribution or reproduction in other forums is permitted, provided the 


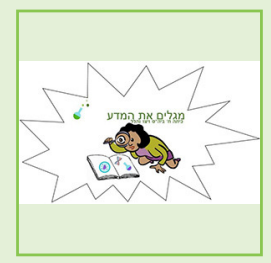

original author(s) and the copyright owner(s) are credited and that the original publication in this journal is cited, in accordance with accepted academic practice. No use, distribution or reproduction is permitted which does not comply with these terms.

\section{YOUNG REVIEWERS}

\section{TH GRADE, WIZO NAHALAL SCHOOL, AGES: 13-14}

We would like to thank Noa Mandelbaum for mentoring us in this paper's review. We are a group of kids for WIZO school in Nahalal: Liri, who enjoys playing basketball; Peleg, who likes playing computer games and editing videos; Neta, who likes dancing; Eyal, who likes painting and meeting new people; Lihi, who likes cooking and baking; and Shira, who likes sports, cooking, and baking.

\section{AUTHORS}

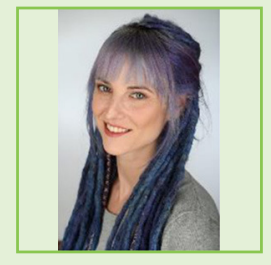

\section{ANNA GOLBERG}

Anna is a master's student in medical science at the Rapaport Faculty of Medicine, at the Technion. In 2017, she graduated with honors with a B.Sc. in biochemical engineering at the Technion. Then, she worked in the industry of composite materials, in the R\&D department. After about a year and a half in the industry, she remembered her childhood dream to clone a colorful ship and decided to return to advanced studies at the Technion, to become a biology researcher. Today she is a part of Prof. Noam Kaplan's lab, which studies the three-dimensional structure and function of the genome.

\section{NAAMA GEVA-ZATORSKY}

Professor Naama Geva-Zatorsky is a researcher at the Technion, in the Rapaport Faculty of Medicine. She completed her double bachelor's degree in chemistry and biology in Tel Aviv University and completed master's and Ph.D. degrees with honors at the Weizmann Institute, in systems biology. She completed her post-doctorate studies at the Harvard School of Medicine. In her lab at the Technion, with a group of 8-10 students and other researchers, she studies the interactions of the gut microbiota with the mammal host, in health and disease. Her lab studies how gut bacteria could complement human physiological functions and promote health.

*naama_gz@technion.ac.il 